\title{
Titanium(IV) Oxide Modified with Activated Carbon and Ultrasounds for Caffeine Photodegradation: Adsorption Isotherm and Kinetics Study
}

\author{
Piotr Zawadzki ${ }^{* *}$, Edyta Kudlek², Mariusz Dudziak ${ }^{3}$ \\ 1 Department of Water Protection, Central Mining Institute, Plac Gwarków 1, 40-166 Katowice, Poland \\ 2 Institute of Water and Wastewater Engineering, Silesian University of Technology, Konarskiego 18, \\ 44-100 Gliwice, Poland \\ 3 Institute of Water and Wastewater Engineering, Silesian University of Technology, Konarskiego 18, \\ 44-100 Gliwice, Poland \\ * Corresponding author's e-mail: pzawadzki@gig.eu
}

\begin{abstract}
In this paper the adsorption and photodegradation of caffeine (CAF) using modified photocatalysts were studied. The laboratory synthesis method of commercial titanium(IV) oxide, activated carbon and ultrasound was proposed. The adsorption effect of caffeine was described by the Langmuir and Freundlich isotherms. The effectiveness of CAF photocatalytic decomposition was evaluated as well as the parameters of the pseudo-first-order and pseudo-second-order reaction kinetics were estimated. It was determined that the caffeine adsorption fit both the Langmuir and Freundlich isotherms. The value of the experimental maximum adsorption capacity $\left(\mathrm{q}_{\mathrm{e}}\right)$ was the highest for $\mathrm{TiO}_{2}$ modified with activated carbon and ultrasounds $\left(\mathrm{TiO}_{2} / \mathrm{AC} / \mathrm{Us}\right)$. The highest removal degree (over $99.0 \%$ ) of CAF was observed for titanium(IV) oxide modified with activated carbon. Both photodegradation kinetics models show good or very good fit; however, the pseudo-first-order model shows better fit to the experimental data $\left(\mathrm{R}^{2}=97-99 \%\right)$. After 20 minutes of the photodegradation process, the following efficiency order was determined: $\mathrm{TiO}_{2}<\mathrm{TiO}_{2} / \mathrm{AC}<\mathrm{TiO}_{2} / \mathrm{AC} / \mathrm{US}$. The results indicate that the combination of $\mathrm{TiO}_{2}$, activated carbon and ultrasound is an interesting alternative for the efficient degradation of caffeine, comparing to commercial $\mathrm{TiO}_{2}$.
\end{abstract}

Keywords: $\mathrm{TiO}_{2}$; caffeine; photocatalysis; modified photocatalysts; activated carbon; ultrasound; kinetics; adsorption

\section{INTRODUCTION}

Micropollutants are a constantly growing group of substances that occur in water and wastewater environment at trace levels (i.e. at the level from $\mathrm{ng} / \mathrm{l}$ to $\mu \mathrm{g} / \mathrm{l})$. An examplary compound belonging to the group of micropollutants is 1,3,7-trimethylxanthine, commonly known as caffeine (CAF). Caffeine is an alkaloid naturally occurring in over 60 species of plants (beans, leaves and fruits etc.). CAF is mainly consumed with drinks such as coffee, tea and energy drinks. Caffeine belongs to natural psychoactive substances. When it is consumed in moderate doses, it is safe for humans. However, an excessive consumption increases the risk of serious toxicity (Turnbull et al., 2017).

The main sources of caffeine for aquatic ecosystems (both marine and freshwater) are anthropogenic sources. Increasing the consumption of caffeine-containing products contributes to the increase of caffeine concentration in wastewater. This is due to the fact that a small amount of caffeine $(0.5-10 \%)$ is completely excreted by the urinary system and enters the wastewater treatment plant. The consequence of untreated or inadequately treated wastewater is the increasing concentration of CAF in aquatic ecosystems. Over the last decade, caffeine has been detected in marine ecosystems, estuarine and coastal waters 
and water inflows at relatively low levels from $<2.0 \mathrm{ng} / 1$ to $5.0 \mu \mathrm{g} / \mathrm{l}$ (Rodriguez et al., 2012).

The presence of micropollutants such as caffeine in the environment determines that the development of new treatment technologies is justified. Advanced oxidation processes (AOPs) are one of such technologies that are of great interest nowadays. AOPs are highly efficient novel methods that accelerate the oxidation and the degradation of a wide range of organic and inorganic substances that are resistant to the conventional treatment methods (Deng \& Zhao 2015). The common feature of AOPs is the production of the $\mathrm{OH}^{*}$ radicals. The mechanism of generating radicals depends on the sort of AOPs technique. Heterogeneous photocatalysis is an example of the AOPs technology, in which the titanium dioxide $\left(\mathrm{TiO}_{2}\right)$ photocatalyst is used. Photocatalytic oxidation process combines UV irradiation at a wavelength of $\lambda \leq 400 \mathrm{~nm}$ with a catalyst (e.g. $\mathrm{TiO}_{2}, \mathrm{CdS}$, $\mathrm{ZnO}$ ). This study focusing on titanium(IV) oxide. From a practical point of view, improving the properties of semiconductors has gained particular interest. Therefore, many scientific papers are focused on the modification of $\mathrm{TiO}_{2}$ (Wang et al., 2018; Hunge et al., 2020; Zawadzki, 2020).

Ultrasonic modification technology is a safe, simple and efficient method for potential use in water and wastewater treatment. Ultrasound improves the $\mathrm{TiO}_{2}$ activity, increases the specific surface area, thus better adsorption of $\mathrm{TiO}_{2}$ on the activated carbon surface can be achieved (Chu et al., 2017; Lee et al., 2017). In turn, activated carbon is a commonly used adsorbent in water and wastewater technology. It has decent quality for a low price (10-12 \$/kg), it is non-toxic, provides a high specific surface $\left(\mathrm{S}_{\mathrm{BET}}\right.$ about $\left.2500 \mathrm{~m}^{2} / \mathrm{g}\right)$ and is a support for $\mathrm{TiO}_{2}$ particles (Pereira et al., 2019). The applied modification method (activated carbon and ultrasound) is not cost consuming and does not require large number of expensive chemical reagents, which is the basis of the principles of green chemistry. Short modification time and simplicity is the advantage of this technology. Due to its simplicity, it can be used in water or wastewater treatment plants.
Titanium(IV) oxide was chosen as the base material for modification. It is non-toxic and stable compared to other catalysts, e.g. $\mathrm{ZnO}$ or $\mathrm{CdS}$. However, it still needs to be modified to improve its properties. A modified photocatalyst should be characterized by better performance than the raw material. The advantages of modified photocatalysts include: higher sorption capacity; stability at variable $\mathrm{pH}$; better pollutants degradation; visible light activity; facilitated post-process recovery (Xing et al., 2016).

Therefore, in this study, the adsorption isotherm and reaction kinetics towards caffeine degradation on modified photocatalysts were determined. The assessment of factors affecting the adsorption and photocatalytic degradation was also conducted.

\section{MATERIALS AND TEST METHODOLOGY}

\section{Materials}

The caffeine model solutions were prepared by dissolving analytical standard of caffeine with $>98 \%$ of purity purchased from Sigma-Aldrich (Poznań, Poland) in deionized water. The $\mathrm{pH}$ of the model solution was adjusted with $0.1 \mathrm{~mol} / 1$ $\mathrm{HCl}$ or $0.1 \mathrm{~mol} / 1 \mathrm{NaOH}$ and monitored using the Elmetron CPC-511 pH-meter (Zabrze, Poland). The conductivity of the model solutions was $0.2 \mathrm{mS} / \mathrm{cm}$. In order to maintain constant ionic strength, the model solutions contained $0.01 \mathrm{~mol} / 1$ of $\mathrm{NaNO}_{3}$.

The commercial titanium dioxide $\mathrm{TiO}_{2}-\mathrm{P} 25$ (anatase/rutile $=80 / 20$ ) was selected as the base material for the modification of photocatalysts. The material was obtained from Evonik Degussa GmbH (Germany). Photocatalysts were modified using commercial, powdered activated carbon CWZ-30 by Gryfskand (Gryfino, Poland). The specification of $\mathrm{TiO}_{2}$ and activated carbon is shown in Table 1.

Table 1. Physicochemical characteristics of $\mathrm{TiO}_{2}$ and activated carbon

\begin{tabular}{|c|c|c|c|c|c|}
\hline Symbol & Origin & Surface area $\mathrm{S}_{\mathrm{BET}}\left[\mathrm{m}^{2} / \mathrm{g}\right]$ & Particle size $[\mathrm{nm}]$ & Granulation [\%] & Density $\left[\mathrm{g} / \mathrm{cm}^{3}\right]$ \\
\hline $\mathrm{TiO}_{2}-\mathrm{P} 25$ & $\begin{array}{c}\text { Evonik Degussa } \\
\text { GmbH (Germany) }\end{array}$ & $50.0 \pm 15.0$ & 21.0 & - & 4.26 \\
\hline $\mathrm{CWZ}-30$ & $\begin{array}{c}\text { Gryfskand (Gryfino, } \\
\text { Poland) }\end{array}$ & 1134.0 & - & 90.0 & $0.28-0.36$ \\
\hline
\end{tabular}




\section{Synthesis of photocatalysts samples}

The photocatalyst samples were prepared based on commercial titanium(IV) oxide and powdery activated carbon (AC). In order to modify the $\mathrm{TiO}_{2}$ samples, a hybrid method of preparation based on mechanical mixing, calcination and ultrasound irradiation has been applied. In the first stage of preparation, a $\mathrm{TiO}_{2}-\mathrm{AC}$ mixture in deionized water $(85: 15, \mathrm{w} / \mathrm{w})$ was prepared. The suspension was stirred for 30 minutes in a dark at room temperature. $\mathrm{The} \mathrm{TiO}_{2} / \mathrm{AC}$ photocatalysts ( $\mathrm{TiO}_{2}$ modified with activated carbon) were prepared as follows: the mixture of $\mathrm{TiO}_{2}-\mathrm{AC}$ was calcined in a CHEMLAND muffle furnace at $300^{\circ} \mathrm{C}$ for 8 hours. Hereby, the $\mathrm{TiO}_{2} / \mathrm{AC}$ precursors were obtained. The $\mathrm{TiO}_{2} / \mathrm{AC} / \mathrm{Us}$ photocatalysts $\left(\mathrm{TiO}_{2}\right.$ modified with activated carbon and ultrasound) were prepared as follows: the mixture of $\mathrm{TiO}_{2}-\mathrm{AC}$ was subjected to ultrasound irradiation in an ultrasonic washer for one hour at $30^{\circ} \mathrm{C}$ using $50 \%$ of the device output power. The process was carried out in the dark. An IS-1K ultrasonic cleaner (InterSonic, Poland) was used with a $50 \mathrm{~Hz}$ operating frequency and a power density of $5 \mathrm{~W} / \mathrm{cm}^{2}$. The device has the ability to work at temperatures up to $80^{\circ} \mathrm{C}$ and smooth power regulation in the range of 10 to $100 \%$. Then, a $\mathrm{TiO}_{2}-\mathrm{AC}$ mixture irradiated with ultrasound was calcined in a CHEMLAND muffle furnace at $300^{\circ} \mathrm{C}$ for 8 hours. This catalyst was denoted as $\mathrm{TiO}_{2} / \mathrm{AC} / \mathrm{Us}$, where 'Us' means modified by ultrasound.

\section{Instruments and analytical methods}

Caffeine was determined using GC-MS-EI chromatographic analysis coupled with a mass detector by Perlan Technologies (Warsaw, Poland). The device was equipped with a $5 \mathrm{SLB}^{\mathrm{TM}}$ - $5 \mathrm{~ms}$ capillary chromatography column with the dimensions of $30.0 \mathrm{~m} \times 0.25 \mathrm{~mm} \times 0.25 \mu \mathrm{m}$ by Sigma-Aldrich (Poznań, Poland). The column heater was programmed in the temperature range from 80 to $300^{\circ} \mathrm{C}$. The stove worked for eight minutes at $80^{\circ} \mathrm{C}$. Then, for five minutes, the temperature was increased by $10^{\circ} \mathrm{C} / \mathrm{min}$ to $300^{\circ} \mathrm{C}$. Helium (flow $1.1 \mathrm{ml} / \mathrm{min}$ ) was used as the carrier phase. The samples of $1 \mu \mathrm{l}$ volume were injected automatically. The samples with the volume of $20 \mathrm{~cm}^{3}$ were separated from the photocatalyst particles using a filtration apparatus connected to a vacuum pump by AGA Labor (Warsaw, Poland). A chromatographic analysis was preceded by Solid Phase Extraction (SPE). The extraction process was carried out on Supelclean ${ }^{\mathrm{TM}}$ ENVI-18 columns. The columns were filled with a silica gel modified with octadecyl groups $\left(\mathrm{C}_{18}\right)$. For the conditioning of the column bed, $5 \mathrm{~cm}^{3}$ of acetonitrile and methanol were used. The bed was washed with distilled water $\left(5 \mathrm{~cm}^{3}\right)$. The compounds adsorbed on the bed were eluted with $3 \mathrm{~cm}^{3}$ of a mixture of acetonitrile and methanol $(60: 40, \mathrm{v} / \mathrm{v})$.

\section{Isotherm studies}

In order to describe the adsorption effect of caffeine, two adsorption isotherm models, i.e. the Langmuir and Freundlich isotherms were used (Table 2). The Langmuir and Freundlich isotherms were used for the mathematical description of adsorption process (Eqs. 1-4). The Langmuir isotherm model (Eqs. 1-2) assumes that the adsorbate forms a monolayer on the adsorbent's surface and that each site may adsorb a single particle, ignoring interactions between them. The Freundlich isotherm (Eqs. 3-4) describes the adsorption on heterogeneous surfaces and microporous adsorbents.

The isotherm studies were carried out as follows: $0.2 \mathrm{~L}$ of a caffeine model solution at a concentration of $0.25-2.0 \mathrm{mg} / \mathrm{l}$ was placed in the flask; a catalyst at a concentration of $100.0 \mathrm{mg} / 1$ was added and shaken vigorously for 20 minutes. The $\mathrm{pH}$ of the model solution was $6.0 \pm 0.5$ over

Table 2. The equation of isotherms

\begin{tabular}{|c|c|c|c|c|}
\hline Model & Equation & \multicolumn{2}{|c|}{ Linear form } \\
\hline Langmuir & $\mathrm{q}_{\mathrm{e}}=\frac{\mathrm{K}_{\mathrm{L}} \mathrm{q}_{\mathrm{m}} \mathrm{C}_{\mathrm{e}}}{1+\mathrm{K}_{\mathrm{L}} \mathrm{C}_{\mathrm{e}}}$ & $(1)$ & $\frac{\mathrm{C}_{\mathrm{e}}}{\mathrm{q}_{\mathrm{e}}}=\frac{1}{\mathrm{q}_{\mathrm{m}}} \cdot \frac{1}{\mathrm{~K}_{\mathrm{L}}}+\frac{\mathrm{C}_{\mathrm{e}}}{\mathrm{q}_{\mathrm{m}}}$ & $(2)$ \\
\hline Freundlich & $\mathrm{q}_{\mathrm{e}}=\mathrm{K}_{\mathrm{F}} \cdot \mathrm{C}_{\mathrm{e}}^{\frac{1}{\mathrm{n}}}$ & $(3)$ & $\log \mathrm{q}_{\mathrm{e}}=\frac{1}{\mathrm{n}} \cdot \log \mathrm{C}_{\mathrm{e}}+\log \mathrm{K}_{\mathrm{F}}$ & $(4)$ \\
\hline
\end{tabular}

where: $\mathrm{q}_{\mathrm{e}}$ - the mass of the adsorbate per unit weight of adsorbent, $\mathrm{mg} / \mathrm{g} ; \mathrm{q}_{\mathrm{m}}$ - the maximum amount of adsorbate required to form monolayer, $\mathrm{mg} / \mathrm{g} ; K_{L}$ - Langmuir isotherm constant, $\mathrm{mg} / \mathrm{g} ; C_{e}-$ adsorbate concentration in equilibrium, $\mathrm{mg} / \mathrm{l} ; K_{F}, n-$ Freundlich isotherm constants 
the temperature $\mathrm{T}=298 \mathrm{~K}$. The process was carried out in a dark.

\section{Photocatalysis experiments}

The photodegradation of caffeine was carried out in a Heraeus reactor with a capacity of $0.7 \mathrm{~L}$. The initial concentration of caffeine in the photodegradation tests was $1.0 \mathrm{mg} / \mathrm{l}$. The batch reactor was equipped with a $150 \mathrm{~W}$ mercury high-pressure lamp. The lamp emits ultraviolet light in the range of 200-580 $\mathrm{nm}$. The UV lamp was placed in a glass jacket cooled by tap water. Therefore, the temperature of reaction solutions was maintained in the range from 20 to $21^{\circ} \mathrm{C}$. The batch reactor was placed on a magnetic stirrer to ensure proper mixing of the reaction mixtures. The reactor was equipped with aeration pump with a capacity of $0.25 \mathrm{~cm}^{3}$ of air per 1 hour. The dose of the catalysts in the photocatalysis process was $0.1 \mathrm{~g} / \mathrm{l}$. Before switching on the radiation source, a 15 minute contact time of adsorption was provided. The adsorption process was carried in the dark. The photodegradation process was carried out continuously for 20 minutes. The samples for the chromatographic analysis were taken at a time intervals of $5 \mathrm{~min}$. All experiments were carried out independently in triplicate.

\section{Kinetics studies}

Most of the kinetic studies were performed using the pseudo-first-order kinetics which is fitted to the Langmuir-Hinshelwood (L-H) model. Under ideal conditions, the L-H model can be expressed by Eq. 5 and Eq. 6. Although it is the most commonly used model to describe the rate of pollutants degradation (Asenjo et al., 2013), pseudo-second-order model (Eq. 7 and Eq. 8) were considered. The equation isotherms are shown in Table 3.

\section{RESULTS AND DISCUSSION}

\section{Effect of sorption time}

Figure 1 presents the effect of caffeine adsorption on catalysts. Caffeine was removed in the range from $25-50 \%$ in $20 \mathrm{~min}$. It can be observed that the maximum adsorption was reached in approx. $15 \mathrm{~min}$ for all the catalysts tested. The rate of caffeine uptake onto commercial catalyst surface $\left(\mathrm{TiO}_{2}\right)$ was the most intense in $5 \mathrm{~min}$ (17\%). In the next minutes (5-15 min) adsorption degree increased slightly to $25 \%$. Over the next 15 to 20 minutes, the increase in the CAF removal was not significant (less than $0.1 \%$ ). Thus, equilibrium was attained within $15 \mathrm{~min}$. The adsorption on modified catalysts was different. In fact, the most intense rate of caffeine adsorption was observed up to $10-12 \mathrm{~min}$. After 15 minutes, adsorption almost stopped at $39 \%$ and $50 \%$ for $\mathrm{TiO}_{2} / \mathrm{AC}$ and $\mathrm{TiO}_{2} / \mathrm{AC} / \mathrm{Us}$, respectively. Therefore, $15 \mathrm{~min}$ was chosen as the optimal adsorption time. The 15 min duration time matches with the studies related to the adsorption of other organic pollutants reported by (Shirsath et al., 2013; Li et al., 2018).

Poor caffeine uptake on commercial $\mathrm{TiO}_{2}$ comparing to modified catalysts is related to its low surface area $\left(\mathrm{S}_{\mathrm{BET}}=50.0 \pm 15.0 \mathrm{~m}^{2} / \mathrm{g}\right)$ and the physico-chemical properties of CAF. Caffeine is characterized by high solubility in water $(21.6 \mathrm{~g} / \mathrm{l})$ and a negative $\log \mathrm{K}_{\mathrm{OW}}$ partition coefficient $(-0.07)$. This means that caffeine is poorly adsorbed on adsorbents, which affects its low removal degree.

The $\mathrm{TiO}_{2} / \mathrm{AC} / \mathrm{Us}$ material showed the highest CAF adsorption performance. The influence of activated carbon and ultrasonic modification on modified catalysts potential for adsorption was observed. First of all, activated carbon has a high active surface area $\left(\mathrm{S}_{\mathrm{BET}}=1134.0 \mathrm{~m}^{2} / \mathrm{g}\right.$ in this study). Bel Hadjltaief et al. (2016) studied

Table 3. The equation of kinetics

\begin{tabular}{|c|c|c|c|c|c|}
\hline Model & \multicolumn{2}{|c|}{ Equation } & \multicolumn{2}{c|}{ Plot } & References \\
\hline Langmuir-Hinshelwood & $-\ln \left(\mathrm{C}_{\mathrm{t}} / \mathrm{C}_{0}\right)=\mathrm{k}_{1} \mathrm{t}$ & $(5)$ & $-\ln \left(\mathrm{C}_{\mathrm{t}} / \mathrm{C}_{0}\right) \mathrm{VS} \mathrm{t}$ & (6) & (Armenise et al., 2013) \\
\hline Pseudo-second-order & $\frac{1}{\mathrm{C}_{\mathrm{t}} / \mathrm{C}_{0}}=\mathrm{k}_{2} \mathrm{t}+\frac{1}{\mathrm{C}_{0}}$ & $(7)$ & $\frac{1}{\mathrm{C}_{\mathrm{t}} / \mathrm{C}_{0}} \mathrm{VS} \mathrm{t}$ & (8) & $\begin{array}{c}\text { (Marcinkowski et al., } \\
\text { 2014) }\end{array}$ \\
\hline
\end{tabular}

where: $\mathrm{C}_{\mathrm{t}}$ - concentration at time $\mathrm{t}, \mathrm{mg} / \mathrm{l} ; \mathrm{C}_{0}$ - initial concentration, $\mathrm{mg} / \mathrm{l} ; \mathrm{k}_{1}$ - pseudo-first-order rate constant; $\mathrm{k}_{2}$ - pseudo-second-order rate constant. 


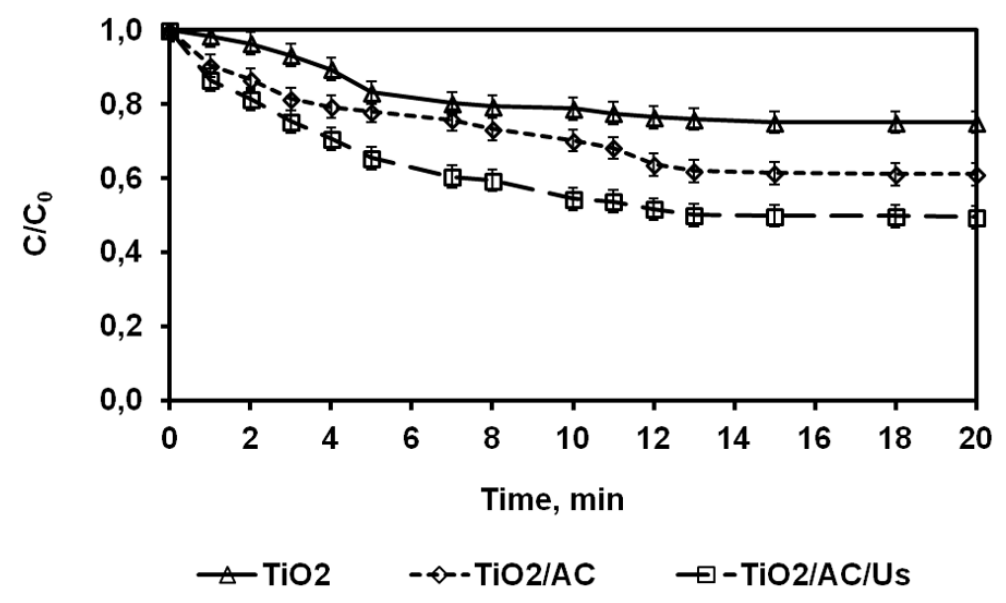

Fig. 1. Influence of sorption time on caffeine removal. Conditions: $\mathrm{TiO}_{2}$ dosage $=0.1 \mathrm{~g} / \mathrm{l}$; caffeine concentration $=1.0 \mathrm{mg} / \mathrm{l} ; \mathrm{pH}=6.0 \pm 0.5$

the effect of activated carbon on the increase of catalyst surface. The authors modified the surface of titanium(IV) oxide by means of activated carbon, which increased the $\mathrm{TiO}_{2}$ active surface area to $420 \mathrm{~m}^{2} / \mathrm{g}$. Afterwards, ultrasonic radiation increased the active surface area by dispersing the solid phase of $\mathrm{TiO}_{2}$. Furthermore, the surface of the modified $\mathrm{TiO}_{2}$ was activated by ultrasound, leading to higher adsorption potential of pollutants, which was confirmed by Bulychev (2019).

\section{Effect of caffeine concentration}

Figure 2 shows the adsorption isotherm of caffeine at $298 \mathrm{~K}$. On the basis of the obtained results, adsorption isotherm was classified by fitting them to the isotherm classification system. The shape of isotherms is the first experimental tool to investigate the nature of a particular adsorption phenomenon. The isotherm classification system presented by Sing (1985) divides the shape of isotherms on six general types. More detailed system of isotherm classification divides all isotherms into four main classes (18 shapes of isotherms) (Giles et al., 1960). A simplified classification system was taken into account. The obtained isotherms are of type I. This means that as the adsorbent pores are filled, the caffeine particles find harder a vacant site to adsorb. Thus, the identified isotherm shapes are the most common, two wellknown equations isotherms, i.e. Langmuir and Freundlich could be applied (Ghosh et al., 2019).

Additionally, the values of the experimental maximum adsorption capacity $\left(\mathrm{q}_{\mathrm{e}}\right)$ were determined (Fig. 2). The maximum adsorption capacity of $\mathrm{TiO}_{2}$ is similar to those reported by Janus et al. (2011). The modified catalysts showed the highest adsorption capacity compared to commercial titanium dioxide. The adsorption capacity depends, among others on the modification

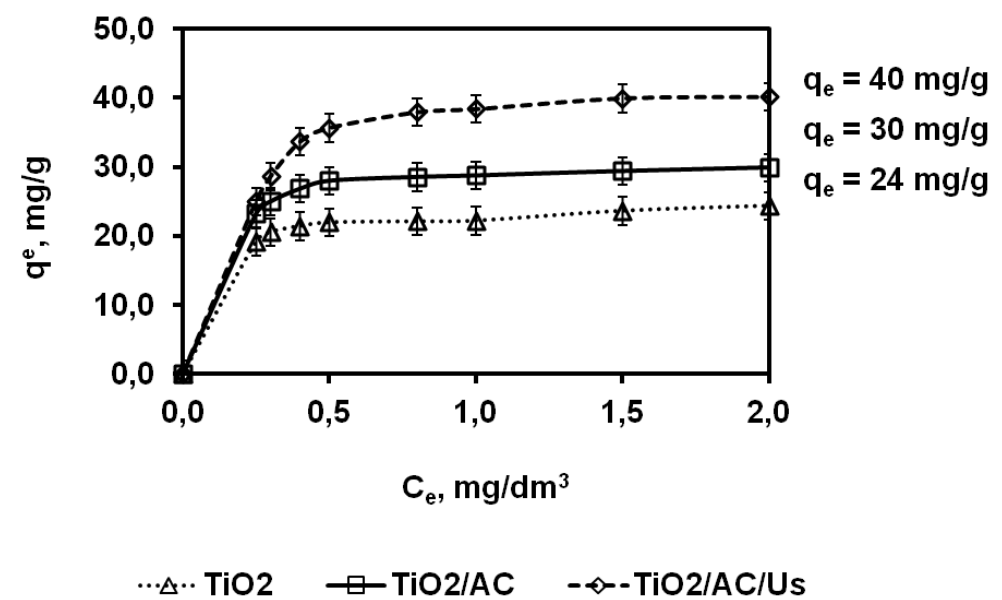

Fig. 2. Effect of caffeine concentration on maximum adsorption capacity. Conditions: $\mathrm{TiO}_{2}$ dosage $=0.1 \mathrm{~g} / \mathrm{l}$; caffeine concentration $=1.0 \mathrm{mg} / \mathrm{l}$; time $=15 \mathrm{~min} ; \mathrm{T}=298 \mathrm{~K}$ 
Table 4. Langmuir and Freundlich isotherm parameters

\begin{tabular}{|c|c|c|c|c|}
\hline Isotherm & Parameter & $\mathrm{TiO}_{2}$ & $\mathrm{TiO}_{2} / \mathrm{AC}$ & $\mathrm{TiO}_{2} / \mathrm{AC} / \mathrm{Us}$ \\
\hline \multirow{3}{*}{ Langmuir } & $a_{m}$ & $0.56 \pm 0.04$ & $1.80 \pm 0.02$ & $1.67 \pm 0.04$ \\
\cline { 2 - 4 } & $K_{L}$ & $6.06 \pm 0.07$ & $0.91 \pm 0.03$ & $0.52 \pm 0.02$ \\
\cline { 2 - 4 } & $R^{2}$ & $0.90 \pm 0.02$ & $0.95 \pm 0.02$ & $0.99 \pm 0.01$ \\
\hline \multirow{3}{*}{ Freundlich } & $n$ & $0.72 \pm 0.03$ & $1.47 \pm 0.04$ & $1.04 \pm 0.02$ \\
\cline { 2 - 4 } & $K_{F}$ & $0.37 \pm 0.02$ & $0.73 \pm 0.02$ & $0.74 \pm 0.02$ \\
\cline { 2 - 4 } & $R^{2}$ & $0.94 \pm 0.02$ & $0.95 \pm 0.03$ & $0.99 \pm 0.01$ \\
\hline
\end{tabular}

method. For example, Jafari et al. (2016) produced an elemental carbon-modified $\mathrm{TiO}_{2}$ at various temperatures. Carbonization at $300^{\circ} \mathrm{C}$ caused an increase in the maximum adsorption capacity by more than 4 times. This study found that the activated carbon-ultrasonic-modified titanium dioxide performs better adsorption potential than the commercial $\mathrm{TiO}_{2}$. The $\mathrm{TiO}_{2} / \mathrm{AC} / \mathrm{Us}$ catalyst proved to be the best adsorption material for caffeine $\left(\mathrm{q}_{\mathrm{e}}=40 \mathrm{mg} / \mathrm{g}\right)$.

\section{Langmuir and freundlich isotherm studies}

Table 4 shows the Langmuir and Freundlich parameters. Langmuir parameter $K_{L}$ indicates the adsorption conditions: unfavourable when $K_{L}>1$, linear when $K_{L}=1$, favourable when $0<K_{L}<1$, and irreversible when $K_{L}=0$ (Ayawei, 2017). Freundlich parameter $n$ in the range within 1-10 shows favourable adsorption (Fierro et al., 2008). A high correlation was found between experimental data and linear isotherms. The correlation coefficient $R^{2}$ showed good or very good fit of the experimental data ( $R^{2}$ ranged from $90 \%$ to $99 \%$ ). It was found that the Freundlich isotherm fit the caffeine adsorption onto pure $\mathrm{TiO}_{2}\left(R^{2}=94 \%\right)$. Furthermore, the adsorption conditions for Langmuir isotherm are unfavourable $\left(K_{L}>1\right)$. Both Langmuir and Freundlich isotherms fit the caffeine adsorption data onto modified photocatalysts. The $\mathrm{R}_{2}$ values are very close to 1 (i.e. $99 \%$ for $\mathrm{TiO}_{2} / \mathrm{AC} / \mathrm{Us}$ ) and adsorption conditions $(n)$ are higher than 1.

\section{Photodegradation study}

In order to determine the photocatalytic activity of the prepared catalysts, a photodegradation study and a kinetics study were carried out. As shown in Fig. 3, the removal of caffeine is time-dependent. The time period from -15 to 0 means adsorption process. A 15 min contact time was selected according to preliminary studies (section 3.1). The implementation of UV radiation (" 0 " time of the process) has started the photodegradation process. The photocatalytic degradation of caffeine was carried out for $20 \mathrm{~min}$. At the end of $20 \mathrm{~min}$ of the reaction, the caffeine degradation was approximately $60 \%$ for pure $\mathrm{TiO}_{2}, 82 \%$ for $\mathrm{TiO}_{2} / \mathrm{AC}$ and $95 \%$ for $\mathrm{TiO}_{2} / \mathrm{AC} / \mathrm{Us}$. Thus, this indicates the synergistic effect between activated carbon and ultrasound. Similar results were reported by Khani et al. (2019). The authors synthesized the catalysts modified with ultrasound. These materials were up to $50 \%$ more active than conventional $\mathrm{TiO}_{2}$.

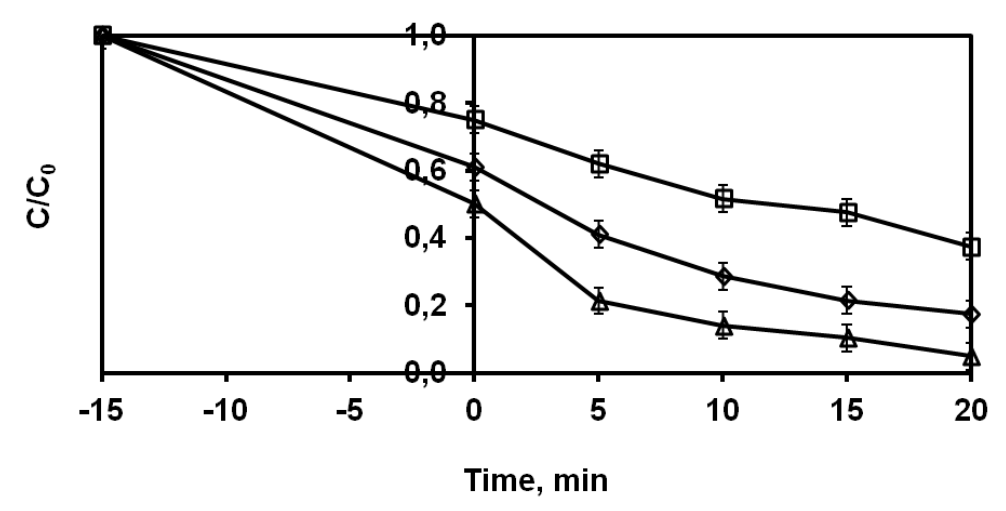

๑TiO2 $\neg$ TiO2/AC $\triangle$ TiO2/AC/Us

Fig. 3. Photodegradation of caffeine. Conditions: $\mathrm{TiO}_{2}$ dosage $=0.1 \mathrm{~g} / \mathrm{l}$; sorption time $=15 \mathrm{~min}$; $\mathrm{pH}=6.0 \pm 0.5 ; \mathrm{T}=298 \mathrm{~K}$ 
The results indicated that in $\mathrm{TiO}_{2} / \mathrm{AC} / \mathrm{Us}$ system caffeine can be remarkably removed to a low level (approx. 80\%) within 5 min, whereas in the $\mathrm{TiO}_{2}$ system in only $35 \%$. Moreover, photocatalysis carried out in the presence of modified photocatalysts requires a shorter degradation time compared to the processes carried out by i.e. Sacco et al. (2019).

Improved photocatalytic performance of modified photocatalysts may be explained in several ways. Enhanced adsorption of caffeine was possible due to the high specific surface area of $\mathrm{TiO}_{2}$ covered by activated carbon; however, the better performance of the ultrasound modified catalyst is attributed to an acoustic cavitation of ultrasound waves. Ultrasounds alter the surface properties, such as surface area and particle size distribution; therefore, the amount of radicals generated during the process increased (Stucchi et al., 2018; Giannakoudakis et al., 2020). Moreover, ultrasounds limit the phenomenon of blocking active sites. The blocking active sites phenomenon is related with poor specific surface area and the generation of byproducts. The identification of intermediates was beyond the scope of this study.

In order to analyze the photodegradation kinetics of caffeine, pseudo-first-order and pseudo second-order reaction were investigated (Fig. 4). Taking into account the relationship between $-\ln \left(C / C_{\theta}\right)$ and reaction time, the two-stage oxidation process, which is a characteristic phenomenon, e.g. for heterogeneous oxidation processes (Covinich et al., 2018) was not found. The two-stage oxidation process is mainly attributed to the indirect reaction of oxygenating species with by-products or decreasing amount of radicals during the reaction.

a)

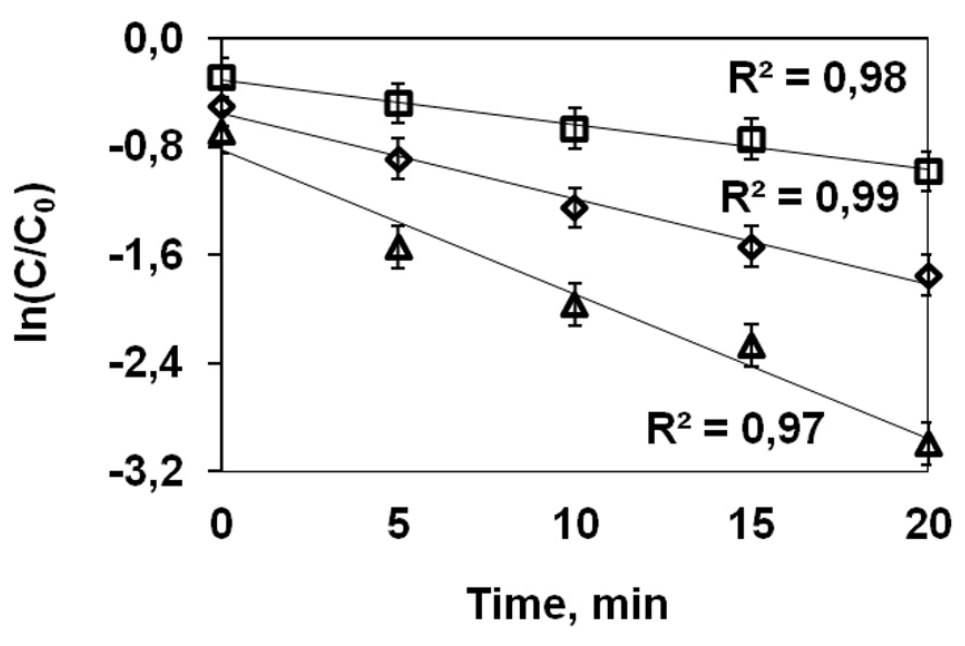

口TIO2 $\diamond$ TIO2/AC $\triangle \mathrm{TiO} 2 / \mathrm{AC} / \mathrm{Us}$

b)

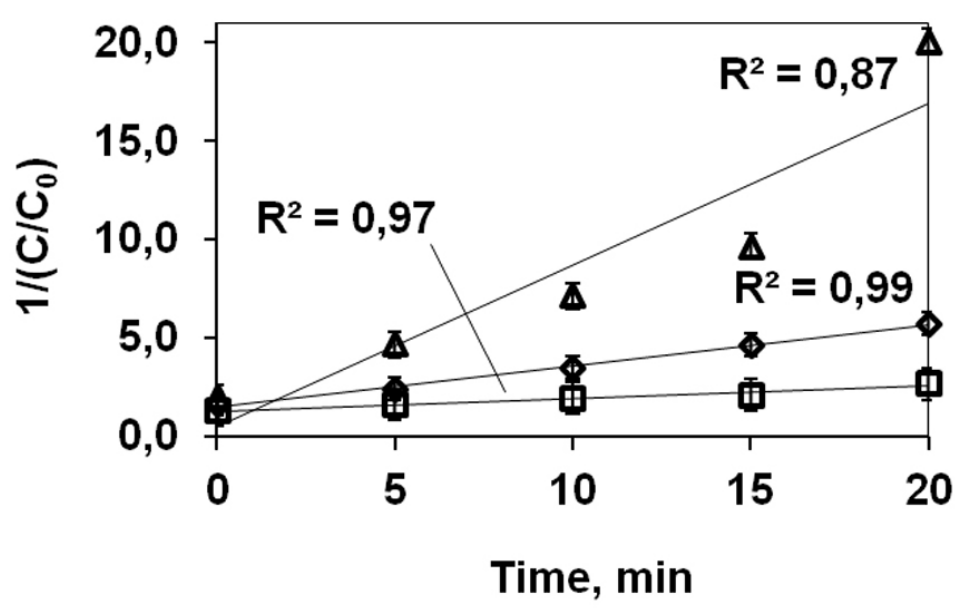

口TIO2 $\diamond$ TIO2/AC $\triangle$ TIO2/AC/Us

Fig. 4. Kinetics of caffeine photodegradation ( $\mathrm{a}$ - Langmuir-Hinshelwood; $\mathrm{b}$ - pseudo-second-order) 
Table 5. Kinetic parameters of the photocatalysis

\begin{tabular}{|c|c|c|c|c|}
\hline \multirow{2}{*}{ Model } & \multirow{2}{*}{ Parameter } & \multicolumn{3}{|c|}{ Catalyst } \\
\cline { 2 - 4 } & & $\mathrm{TiO}_{2}$ & $\mathrm{TiO}_{2} / \mathrm{AC}$ & $\mathrm{TiO}_{2} / \mathrm{AC} / \mathrm{US}$ \\
\hline \multirow{2}{*}{ Pseudo-first-order } & $k, 1 / \mathrm{min}$ & 0.033 & 0.063 & 0.107 \\
\cline { 2 - 5 } & $R^{2}$ & 0.98 & 0.99 & 0.97 \\
\hline \multirow{2}{*}{ Pseudo-second-order } & $k, 1 / \mathrm{min}$ & 0.063 & 0.208 & 0.822 \\
\cline { 2 - 5 } & $R^{2}$ & 0.97 & 0.99 & 0.87 \\
\hline
\end{tabular}

The presented parameters were calculated from the slopes of the plots and are presented in Table 5. As it was shown, both models are well fitted and show good or very good fit $\left(R^{2}>87 \%\right)$. However, the pseudo-first-order model shows better fit to the experimental data $\left(R^{2}=97-99 \%\right)$. Pseudo-first-order rate constant $k$ becomes twice faster by activated carbon modification and 3.2-fold faster by combination of activated carbon and sonochemical treatment. These changes can be explained by particle size distribution, inhibition of nanoparticles agglomeration and inhibition of electron-hole recombination (Ambati \& Gogate, 2018; Prasad et al., 2011).

\section{CONCLUSION}

The effectiveness of the commercial titanium(IV) oxide and modified photocatalysts for the photocatalytic degradation of caffeine were studied. Modified catalysts were synthesized by activated carbon and sonochemical method using commercial $\mathrm{TiO}_{2}$ as a starting material. It was observed that the physicochemical characteristics of caffeine influenced the uptake and photodegradation by photocatalysts. The results showed that the caffeine uptake by a modified catalyst followed both the Langmuir and Freundlich models. The general results of this study showed that $\mathrm{TiO}_{2}$ modified with activated carbon and ultrasound promotes surface adsorption of caffeine with a maximum adsorption capacity and removal efficiency of $40 \mathrm{mg} / \mathrm{g}$ and $95 \%$, respectively. In overall, the photodegradation of caffeine followed the pseudofirst-order kinetics. After 20 minutes of the photodegradation process, the following efficiency order was determined: $\mathrm{TiO}_{2}<\mathrm{TiO}_{2} / \mathrm{AC}<\mathrm{TiO}_{2} / \mathrm{AC} / \mathrm{US}$.

\section{REFERENCES}

1. Ambati R., Gogate P.R. 2018. Ultrasound Assisted Synthesis of Iron Doped $\mathrm{TiO}_{2}$ Catalyst. Ultrasonics Sonochemistry, 40, Part A, 91-100. https://doi. org/10.1016/j.ultsonch.2017.07.002
2. Armenise S., Garcia-Bordeje E., Valverde J.L., Romeo E., Monzon A. 2013. A Langmuir-Hinshelwood approach to the kinetic modelling of catalytic ammonia decomposition in an integral reactor. Physical Chemistry Chemical Physics, 15, 12104-12117. https://doi.org/10.1039/C3CP50715G

3. Asenjo N.G., Santamaria R., Blanco C., Granda M., Alvarez P., Menendez R. 2013. Correct use of the Langmuir-Hinshelwood equation for proving the absence of a synergy effect in the photocatalytic degradation of phenol on a suspended mixture of titania and activated carbon. Carbon, 55, 62-69, https://doi.org/10.1016/j.carbon.2012.12.010

4. Ayawei N. 2017. Modelling and interpretation of adsorption isotherms. Journal of Chemistry, 2017, 3039817. https://doi.org/10.1155/2017/3039817

5. Bel Hadjltaief H., Omri A., Zina M.B., Da Costa P., Galvez M.E. 2016. Titanium dioxide supported on different porous materials as photocatalyst for the degradation of methyl green in wastewaters. Advances in Materials Science and Engineering, 2015, 759853, 1-10. http://dx.doi. org $/ 10.1155 / 2015 / 759853$

6. Bulychev N.A. 2019. Surface modification of titanium dioxide under ultrasonic treatment. International Journal of Recent Technology and Engineering, 8(4), 4137-4140. https://doi.org/ 10.35940/ ijrte.C5900.118419

7. Chu K.H., Al-Hamadani Y.A.J., Park C.M., Lee G., Jang M., Jang A., Her N., Son A., Yoon Y. 2017. Ultrasonic treatment of endocrine disrupting compounds, pharmaceuticals, and personal care products in water: a review. Chemical Engineering Journal, 327, 629-647. https://doi.org/10.1016/j.cej.2017.06.137

8. Covinich L., Felissia F., Massa P., Fenoglio R., Area M.C. 2018. Kinetic modeling of a heterogeneous Fenton-type oxidative treatment of complex industrial effluent. International Journal of Industrial Chemistry, 9, 215-229. https://doi.org/10.1007/ s40090-018-0151-6

9. Deng Y., Zhao R. 2015. Advanced oxidation processes (AOPs) in wastewater treatment. Water Pollution, 1, 167-176. https://doi.org/10.1007/ s40726-015-0015-z

10. Ghosh M., Manoli K., Shen X., Wang J., Ray A.K. 2019. Solar photocatalytic degradation of caffeine with dioxide and zinc oxide nanoparticles. Journal of Photochemistry and Photobiology A: Chemistry, 377, 1-7. ttps://doi.org/10.1016/j. 
jphotochem.2019.03.029

11. Giannakoudakis D.A., Farahmand N., Łomot D., Sobczak K., Bandosz T.J., Colmenares J.C. 2020. Ultrasound-activated $\mathrm{TiO}_{2} / \mathrm{GO}$-based bifunctional photoreactive adsorbents for detoxification of chemical warfare agent surrogate vapors. Chemical Engineering Journal, 395, 125099. https://doi. org/ 10.1016/j.cej.2020.125099

12. Giles C.H., MacEwan T.H., Nakhwa S.N., Smith D. 1960. Studies in adsorption. Part XI A system of classification of solution adsorption isotherms, and its use in diagnosis of adsorption mechanisms and in measurement of specific surface areas of solids, Journal of the Chemical Society, 0, 111, 3973-3993. https://doi.org/10.1039/JR9600003973

13. Hunge, Y.M., Yadav A.A., Dhodamani A.G., Suzuki N., Terashima C., Fujishima A., Mathe V.L. 2020. Enhanced photocatalytic performance of ultrasound treated $\mathrm{GO} / \mathrm{TiO}_{2}$ composite for photocatalytic degradation of salicylic acid under sunlight illumination. Ultrasonics Sonochemistry, 61, 104849. https://doi. org/10.1016/j.ultsonch.2019.104849

14. Jafari S., Yahyaei B., Kusiak-Nejman E., Sillanpaa M. 2016. The influence of carbonization temperature on the modification of $\mathrm{TiO}_{2}$ in the removal of methyl orange from aqueous solution by adsorption. Desalination and Water Treatment, 57, 18825-18835. https://doi.org/10.1080/19443994.2015.1094678

15. Janus M., Kusiak-Nejman E., Morawski A.W. 2011. Determination of the photocatalytic activity of TiO2 with high adsorption capacity. Reaction Kinetics, Mechanisms and Catalysis, 103, 279-288. https:// doi.org/10.1007/s11144-011-0326-Z

16. Khani Z., Schieppati D., Bianchi C.L., Boffito D.C. 2019. The Sonophotocatalytic Degradation of Pharmaceuticals in Water by $\mathrm{MnOx}-\mathrm{TiO}_{2}$ Systems with Tuned Band-Gaps. Catalysts, 9, 949. https://doi. org/10.3390/catal9110949

17. Lee J.Y., Jo W.K., 2017. Application of ultrasoundaided method for the synthesis of CdS-incorporated three-dimensional $\mathrm{TiO}_{2}$ photocatalysts with enhanced performance. Ultrasonics Sonochemistry, 35(A), 440-448. https://doi.org/10.1016/j. ultsonch.2016.10.023

18. Li Q., Pan F., Li W., Li D., Xu H., Xia D., Li A. 2018. Enhanced Adsorption of Bisphenol A from Aqueous Solution with 2-Vinylpyridine Functionalized Magnetic Nanoparticles. Polymers, 10, 1136. https://doi.org/10.3390/polym10101136

19. Marcinkowski D., Wałęsa-Chorab M., Patroniak V., Kubicki M., Kądziołka G., Michalkiewicz B. 2014. A New polymeric complex of silver(I) with a hybryd pyrazine-bipyridine ligand - synthesis, crystal structure and its photocatalytic activity. New Journal of Chemistry, 38, 604-610. https://doi.org/10.1039/c3nj01187a

20. Pereira L.O., Sales I.M., Zampiere L.P., Vieira S.S., Guimaraes I.R., Magalhaes F. 2019. Preparation of magnetic photocatalysts from $\mathrm{TiO}_{2}$, activated carbon and iron nitrate for environmental remediation. Journal of Photochemistry and Photobiology A: Chemistry, 382, 111907. https://doi.org/10.1016/j. jphotochem.2019.111907

21. Prasad K., Pinjari D.V., Pandit A.B., Mhaske S.T. 2011. Synthesis of zirconium dioxide by ultrasound assisted precipitation: effect of calcination temperature. Ultrasonics Sonochemistry, 18(5), 1128-1137. https://doi.org/10.1016/j.ultsonch.2011.03.001

22. Rodriguez R.Z., Granek E.F., Sylvester S. 2012. Occurrence and concentration of caffeine in Oregon coastal waters. Marine Pollution Bulletin, 64(7), 1417-1424. https://doi.org/10.1016/j. marpolbul.2012.04.015

23. Sacco O., Sannino D., Matarangolo M., Vaiano V. 2019. Room temperature synthesis of V-Doped $\mathrm{TiO}_{2}$ and its photocatalytic activity in the removal of caffeine under UV Irradiation. Materials, 12(911), 1-10. https://doi.org/10.3390/ma12060911

24. Shirsath S.R., Pinjari D.V., Gogate P.R., Sonawane S.H., Pandit A.B. 2013. Ultrasound assisted synthesis of doped $\mathrm{TiO}_{2}$ nano-particles: characterization and comparison of effectiveness for photocatalytic oxidation of dyestuff effluent. Ultrasonics Sonochemistry, 20, 277-286. https://doi.org/ 10.1016/j. ultsonch.2012.05.015

25. Sing K.S.W. 1985. Reporting physisorption data for gas/solid systems with special reference to the determination of surface area and porosity. Pure \& Appl. Chem., 57, 4, 603-619. https://doi.org/10.1351/ pac198557040603

26. Stucchi M., Bianchi C.L., Argirusis C., Pifferi V., Neppolian B., Cerrato G., Boffito D.C. 2018. Ultrasound Assisted Synthesis of Ag-Decorated $\mathrm{TiO}_{2}$ Active in Visible Light. Ultrasonics Sonochemistry, 40, 282-288. https://doi.org/10.1016/j. ultsonch.2017.07.016

27. Turnbull D., Rodricks J.V., Mariano G.F., Chowdhury F. 2017. Caffeine and cardiovascular health. Regulatory Toxicology and Pharmacology, 89, 165-185, https://doi.org/ 10.1016/j.yrtph.2017.07.025

28. Wang L., Guo J., Dang J., Huang X., Chen S.S., Guan W. 2018. Comparison of the photocatalytic performance of $\mathrm{TiO}_{2} / \mathrm{AC}$ and $\mathrm{TiO}_{2} / \mathrm{CNT}$ nanocomposites for methyl orange photodegradation. Water Science \& Technology, 78(5-6), 1082-1093. https:// doi.org/10.2166/wst.2018.374

29. Xing B., Shi C., Zhang C., Yi G., Chen L., Guo H., Huang G., Cao J. 2016. Preparation of AC/ $\mathrm{TiO}_{2}$ composites from activated carbon modified by $\mathrm{HNO}_{3}$ and their photocatalytic activity. Journal of Nanomaterials, 2016(1-10), https://doi. org/10.1155/2016/8393648

30. Zawadzki, P. 2020. TiO modified with organic acids for the decomposition of chlorfenvinphos under the influence of visible light: activity, performance, adsorption, and kinetics. Materials, 13(2), 289. https:// doi.org/ 10.3390/ma13020289 